\title{
Physical Programming: A Review of the State of the Art
}

\author{
Mehmet Ali ILGIN ${ }^{1}$, Surendra M. GUPTA ${ }^{2}$ \\ ${ }^{1}$ Celal Bayar University, Muradiye Campus, \\ Manisa, 45140, Turkey, \\ mehmetali.ilgin@cbu.edu.tr \\ 2 Northeastern University, MIE Dept., \\ 360 Huntington Avenue, Boston, MA, 02115, USA, \\ gupta@neu.edu
}

Abstract: Most traditional multi-criteria optimization techniques require that the decision maker construct an aggregate objective function using the weights determined as a result of a trial and error process. Physical programming (PP) eliminates this tedious weight assignment process by providing decision makers with a flexible and more natural problem formulation. In PP, the decision maker specifies ranges of different degrees of desirability instead of defining weights. In this paper, we present a comprehensive review of PP studies by classifying them into four major categories (viz., methodological papers, industrial engineering applications, mechanical engineering applications and other applications). Insights from the review and future research directions conclude the paper.

Keywords: physical programming, multi-criteria optimization, review.

\section{Introduction}

Most real world decision making and design problems are inherently multi-objective. Yet, many mathematical programming methods (e.g., goal programming, analytical hierarchy process) require the decision maker (DM) to assign physically meaningless weights to express his (her) preferences. Physical programming (PP) avoids the weight assignment by providing preference functions. In PP, DM determines a suitable preference function and specifies ranges of different degrees of desirability (desirable, tolerable, undesirable, etc.) for each criterion. There are eight preference functions classified into 8 classes, 4 soft and 4 hard.

\section{Soft Classes:}

Class 1S (smaller-is-better, i.e., minimization)

Class 2S (larger-is-better, i.e., maximization)

Class 3S (value-is-better)

Class 4S (range-is-better)

Hard Classes:

Class $1 \mathrm{H}$ (must be smaller)

Class 2H (must be larger)

Class 3H (must be equal)

Class $4 \mathrm{H}$ (must be in range)

It must be noted that selection of hard or soft classes depends on the sharpness of the preference defined by the DM. The properties of class functions are listed below Kongar and Gupta [14]:

- A lower value of a class function is preferred over a higher value thereof.
- A class function is strictly positive.

- Class function is continuous, piecewise linear and convex.

- The value of a class function, $z_{u}$, at a given ranges-intersection (say, desirabletolerable) is the same for any class-type.

After defining class functions for each objective, the following minimization is performed for soft classes:

$$
\min _{x} g(x)=\frac{1}{n_{s c}} \sum_{i=1}^{n_{s c}} \bar{g}_{i}\left(f_{i}(x)\right)
$$

subject to

$$
\begin{aligned}
& f i(x) \leq f i 5 \quad \text { (for Class 1S objectives) } \\
& f i(x) \geq f i 5 \quad \text { (for Class 2S objectives) } \\
& f i 5 L \leq f i(x) \leq f i 5 R \quad \text { (for Class } 3 \text { S objectives) } \\
& f i 5 L \leq f i(x) \leq f i 5 R \quad \text { (for Class } 4 \text { S objectives) }
\end{aligned}
$$

and for hard classes, invoke constraint

$$
\begin{array}{ll}
f_{i}(x) \leq f_{i M} & \text { (for Class 1H objectives) } \\
f_{i}(x) \geq f_{i m} & \text { (for Class 2H objectives) } \\
f_{i}(x)=f_{i v} & \text { (for Class 3H objectives) } \\
f_{i m} \leq f_{i}(x) \leq f_{i M} & \text { (for Class 4H objectives) } \\
x_{j m} \leq x_{j} \leq x_{j M} & \text { (for design var. constraints) }
\end{array}
$$

where $f_{i m}, f_{i M}, x_{j m}$ and $x_{j M}$ represent minimum and maximum values, $f_{\text {iv }}$ helps define the equality constraints; the range limits are provided by the designer (see Figure 1), and $n_{s c}$ is the number of soft objectives that the problem comprises. The above problem model conforms to the 


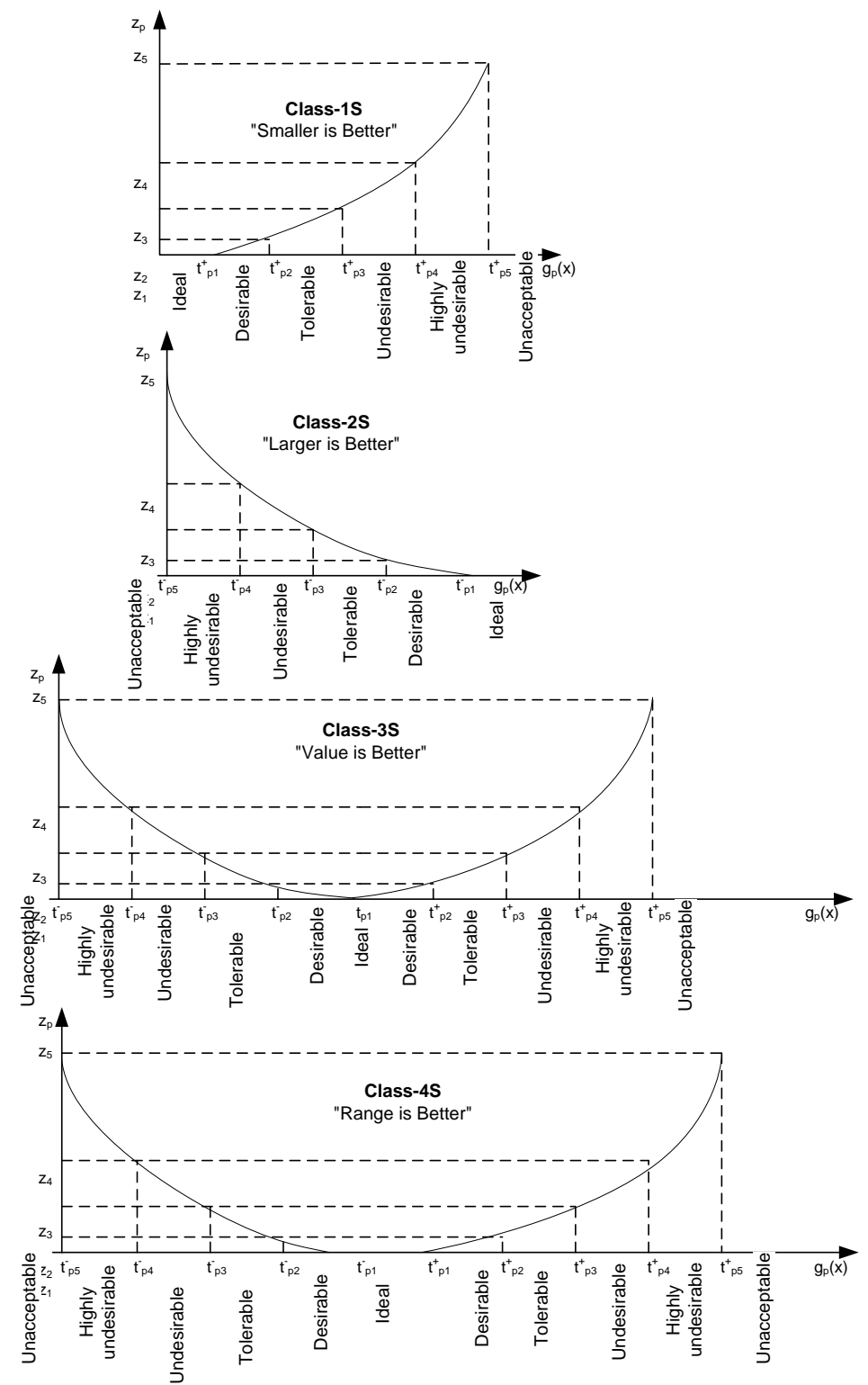

Figure 1. Soft class functions for physical programming

framework of most nonlinear programming codes, with possible minor rearrangements.

The purpose of this paper is to provide an overview of the PP literature. The literature is organized into four main areas: methodological papers, industrial engineering applications, mechanical engineering applications and other applications. Papers are classified into subcategories in each main area. Section 2 presents the papers which make methodological contributions by modifying the original physical programming methodology. The papers investigating the application of PP to Industrial Engineering and Mechanical Engineering related problems are discussed in Sections 3 and 4, respectively. Section 5 reviews the other application papers. Finally, some concluding remarks and future research directions are presented in Section 6.

\section{Methodological Papers}

Different variants of PP were developed by researchers by modifying original PP algorithm. In this section we present general characteristics of these methods.

\subsection{Linear physical programming}

Linear Physical Programming (LPP) developed by Messac et al. simplifies physical programming procedure since preference functions in LPP are piecewise linear [39], 
[27]. The following four steps are followed while applying linear physical programming:

1. One of the four classes is specified by decision maker (DM) for each criterion.

2. The limits of the ranges of differing degrees of desirability (see Figure 2) are defined by DM for each criterion.

3. Based on the DM preferences defined in steps 1 and 2, LPP weight algorithm is used to calculate incremental weights as follows:

\section{Initialize:}

$\beta=1.1 ; w_{q 1}^{+}=0, w_{q 1}^{-}=0, \tilde{z}^{2}=$ small positive number (say, 0.1 ) $q=0 ; s=1, n_{s c}=$ number of soft criteria.
II. Set $q=q+1$
III. Set $s=s+1$

Evaluate, in sequence,

$\tilde{z}^{s}, \tilde{t}_{q s}^{+}, \tilde{t}_{q s}^{-}, w_{q s}^{+}, w_{q s}^{-}, \tilde{w}_{q s}^{+}, \tilde{w}_{q s}^{-}, \tilde{w}_{\min }$

If $\tilde{w}_{\min }$ is less than some chosen small positive number (say, 0.01 ), then increase $\beta$, and go to II.

IV. If $s \neq 5$, go to III.

V. If $i \neq n_{s c}$, go to II.

where $q$ is the index for the soft criteria, $\beta$ is a convexity parameter, $p$ is the index for the hard criteria, $s$ is the index for the range, $w_{q s}^{+}$and $w_{q s}^{-}$are positive and negative weights, respectively, for criteria $q$ in the sth range; $z_{q}$ is

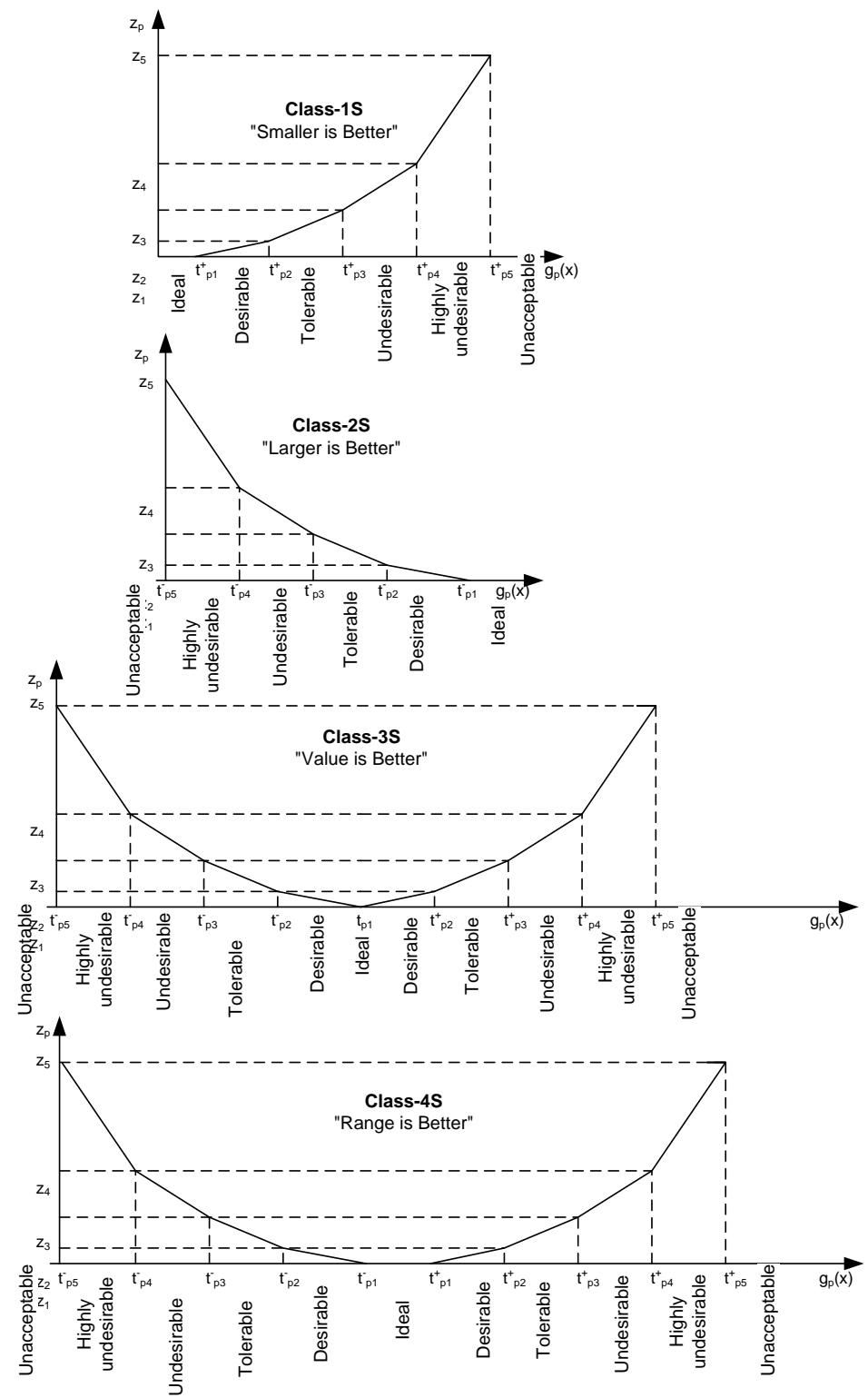

Figure 2. Soft class functions for linear physical programming 
the class function for criteria $q$; $\tilde{z}^{s}$ is the change in $Z_{q}$ that takes place as one travels across the sth range, $\tilde{t}_{q s}^{+}$and $\tilde{t}_{q s}^{-}$are the lengths of the sth ranges on the positive and negative sides of the $q$ th criteria, $\tilde{w}_{q s}^{+}$and $\tilde{w}_{q s}^{-}$are positive and negative normalized weights, respectively, for criteria $q$ in the sth range, $\tilde{w}_{\text {min }}$ is the minimum of $\tilde{w}_{q s}^{+}$and $\tilde{w}_{q s}^{-}$.

4. A total score (J) for each alternative is calculated as a weighted sum of deviations over all ranges and criteria as follows:

$$
\min _{d_{q s}^{-}, d_{q s}^{+}, x} J=\sum_{q=1}^{n_{s c}} \sum_{s=2}^{5}\left(\tilde{w}_{q s}^{-} \cdot d_{q s}^{-}+\tilde{w}_{q s}^{+} \cdot d_{q s}^{+}\right)
$$

\subsection{Fuzzy physical programming}

A technique called fuzzy physical programming was developed by Tian et al. [68] by integrating the fuzziness into the physical programming structure. As shown in Figure 3, with certain parameters, $X$, the design objective value of determinate system is a certain value, $g_{i}(X)$, while the design objective value of fuzzy system is a fuzzy set, $\tilde{g}_{i}(X)$, which is represented using normal membership function as follows:

$\mu_{\tilde{g}_{i}(x)}\left(g_{i}\right)=e^{-\left[\frac{g_{i}-g_{i}(x)}{\delta_{i}}\right]^{2}}, \quad \delta_{i}>0$

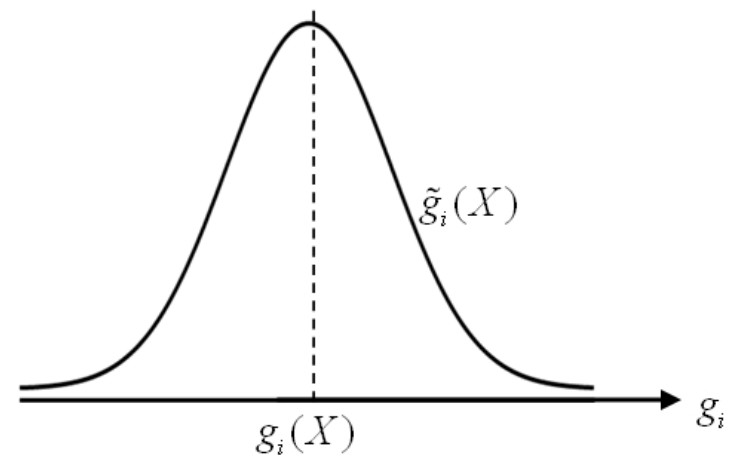

Figure 3: Fuzzy Design Objective Value

Function $f p_{i}\left(\tilde{g}_{i}(X)\right)$ is used to represent the preference function associated with fuzzy set, $\tilde{g}_{i}(X) . f p_{i}\left(\tilde{g}_{i}(X)\right)$ takes the following form:

$$
f p_{i}\left(\tilde{g}_{i}(X)\right)=\frac{\int_{g_{i}(x)-3 \delta_{i}}^{g_{i}(x)+3 \delta_{i}} \bar{g}_{i}\left(g_{i}\right) \cdot \mu_{\tilde{g}_{i}(x)}\left(g_{i}\right) d g_{i}}{\int_{g_{i}(x)-3 \delta_{i}}^{g_{i}(x)+3 \delta_{i}} \mu_{\tilde{g}_{i}(x)}\left(g_{i}\right) \cdot d g_{i}}
$$

The fuzzy aggregate objective function, $f p(X)$, is formulated by synthesizing the fuzzy preference functions for all the design metrics:

$$
f p(X)=\log _{10}\left\{\frac{1}{n_{s c}} \sum_{i=1}^{n_{c}} f p_{i}\left(\tilde{g}_{i}(X)\right)\right\}
$$

Using this aggregate objective function, the fuzzy physical programming model can be written as follows:

$$
\begin{array}{ll}
\min _{X} f p(X)=\log _{10}\left\{\frac{1}{n_{s c}} \sum_{i=1}^{n_{s c}} f p_{i}\left(\tilde{g}_{i}(X)\right)\right\} \\
\text { st } \quad g_{i}(X) \leq g_{i 5} & \text { (for Class 1S) } \\
g_{i}(X) \geq g_{i 5} & \text { (for Class 2S) } \\
g_{i 5 L} \leq g_{i}(X) \leq g_{i 5 R} & \text { (for Class 3S and 4S) } \\
g_{i}(X) \leq g_{i M} & \text { (for Class 1H) } \\
g_{i}(X) \geq g_{i M} & \text { (for Class 2H) } \\
g_{i m} \leq g_{i}(X) \leq g_{i M} & \text { (for Class 3H and 4H) } \\
x_{j m} \leq x_{j} \leq x_{j M} &
\end{array}
$$

\subsection{Global physical programming}

A variant of PP was developed by Sanchis et al. [63] by making the following two modifications in the original PP methodology:

- Preference functions are constructed using a simpler algorithm.

- The optimizer is replaced by a genetic algorithm that avoids possible local minima problems.

Preference functions are constructed considering the following two principles:

- The best result for each objective is translated into the solution of a minimization problem.

- The limits of each preference range present the same image in the class function for all objectives of the multi objective optimization problem. This ensures that the same preference in each objective will have the same image in all class functions. In 
other words, each preference range will weigh the same in the single aggregate objective to be optimized.

The images $\alpha_{k}$ at the range boundaries $g_{i k}$ are calculated as follows:

$\alpha_{0}=0$

$\alpha_{1}=\alpha_{i n i}, \quad \alpha_{i n i} \geq 0$

$\alpha_{k}=\alpha_{k-1} \cdot N_{o b j s} \quad(1<k \leq N)$

where $N_{o b j s}$ is the number of design objectives that the problem comprises and $N$ is the number of preference ranges that the designer wants to manage for the whole multi-objective problem.

It must be noted that these values are equal for all the class functions defined. Hence, the preference intervals defined for each objective $g_{i}(\mathrm{x})$ always produce the same $\Delta \alpha_{k}$ image change in their associated class function.

Based on the above assumptions, they define a new definition for class functions, as polynomials in $g_{i}(\mathrm{x})$ as follows:

\section{Class 1S function}

There are $N+1$ extreme range points, $g_{i}^{k}$, which are used for the quantification of the preferences associated with the design objective. Each objective function will be divided into $N$ intervals with an associated preference. The extreme points $g_{i}^{k}$ are specified in ascending order and the first point $g_{i}^{0}$ is the best value for the design objective.

At the generic interval $k(\mathrm{k} \in[1,2, \ldots, N])$, the class function takes the following form:

$$
f_{k}(x)=\alpha_{k-1}+\Delta \alpha_{k} \cdot\left(\frac{g_{i}(x)-g_{i}^{k-1}}{g_{i}^{k}-g_{i}^{k-1}}\right)^{n}
$$

where $\Delta \alpha_{k}=\alpha_{k}-\alpha_{k-1}$ and $\mathrm{n}>0$ expresses the degree of desirability that the solution reaches the range extremes in the objective space.

As a result, for the $i^{\text {th }}$ objective the class $1 S$ function can be defined as

$$
n_{i}^{1 S}(x)=\left\{\begin{array}{cl}
f_{N}(x) & \text { if } g_{i}(x)>g_{i}^{N} \\
f_{k}(x) & \text { if } g_{i}(x) \in\left[\mathrm{g}_{\mathrm{i}}^{k-1}, \ldots, \mathrm{g}_{i}^{k}\right], k \in[1,2 \ldots, N] \\
0 & \text { if } \mathrm{g}_{\mathrm{i}}(\mathrm{x})<\mathrm{g}_{i}^{0}
\end{array}\right.
$$

\section{Class 2S function}

In this case, points $g_{i}^{k}$ will be specified in ascending value too. However, lower preference for the first values and greater preference for the later values are expressed. For the generic interval $k$, the class function at this interval takes the form

$$
f_{k}(x)=\alpha_{k-1}+\Delta \alpha_{k} \cdot\left(\frac{g_{i}^{k-1}-g_{i}(x)}{g_{i}^{k-1}-g_{i}^{k}}\right)^{n}
$$

And, for the ith objective the class 2S function can be defined as

$$
n_{i}^{2 S}(x)= \begin{cases}f_{N}(x) & \text { if } g_{i}(x)<g_{i}^{N} \\ f_{k}(x) & \text { if } g_{i}(x) \in\left[\mathrm{g}_{i}^{k-1}, \ldots, \mathrm{g}_{i}^{k}\right], k \in[1,2 \ldots, N] \\ 0 & \text { if } g_{i}(x)>\mathrm{g}_{i}^{0}\end{cases}
$$

\section{Class 3S function}

In this case, $2 N+1$ values are specified. $g_{i}^{0}$ is the ideal value and there are $N$ left and right ranges with the values $g_{i}^{k L}$ (left) and $g_{i}^{k R}$ (right) for $k \in[1,2, \ldots, N]$. Class function $2 S$ represents the left ranges represent while a $1 \mathrm{~S}$ function represents the right ranges. Hence, the 3S class function is written as follows:

$$
n_{i}^{3 S}(x)=\left\{\begin{array}{ccc}
n_{i}^{1 S}(\mathrm{x}) & \text { if } \mathrm{g}_{\mathrm{i}}(\mathrm{x})>\mathrm{g}_{\mathrm{i}}^{0} \\
0 & \text { if } \mathrm{g}_{\mathrm{i}}(\mathrm{x})=\mathrm{g}_{i}^{0} \\
n_{i}^{2 S}(\mathrm{x}) & \text { if } \mathrm{g}_{\mathrm{i}}(\mathrm{x})>\mathrm{g}_{\mathrm{i}}^{0}
\end{array}\right.
$$

\section{Class 4S function}

The extreme points $g_{i}^{0 L}$ and $g_{i}^{0 R}$ represent the ideal range. In addition, $N$ left (Class 2S) and right (Class 1S) ranges are defined. Thus, the $4 \mathrm{~S}$ class function is written as follows:

$n_{i}^{4 S}(x)=\left\{\begin{array}{cl}n_{i}^{1 S}(\mathrm{x}) & \text { if } \mathrm{g}_{\mathrm{i}}(\mathrm{x})>\mathrm{g}_{\mathrm{i}}^{0 R} \\ 0 & \text { if } \mathrm{g}_{i}^{0 L}(\mathrm{x})=\mathrm{g}_{i}^{0 R} \\ n_{i}^{2 S}(\mathrm{x}) & \text { if } \mathrm{g}_{\mathrm{i}}(\mathrm{x})>\mathrm{g}_{\mathrm{i}}^{0 L}\end{array}\right.$

$\min _{x} J(\mathrm{x})=\min _{x} \sum_{i=1}^{N_{\text {obis }}} n_{i}(x)$

s.t. $h_{j}(x) \geq 0$

$x_{p}^{m} \leq x_{p} \leq x_{p}^{M}$

where $\mathrm{x} x \in \mathfrak{R}^{p}$ are the vector of design variables, $N_{\text {objs }}$ is the number of objective 
functions, $h_{j}(x)$ is the $j$ th inequality constraint, and the $p^{\text {th }}$ variable varies in the range $\left[x_{p}^{m}\right.$, $x_{p}^{M} \quad$ ]. All class function images (equally weighted) are added to obtain the cost index.

\subsection{Interactive physical programming}

An interactive physical programming framework was proposed by Tappeta et al. [67] which considers decision maker's preferences during the optimization process and allows for the efficient design exploration around a given Pareto point. Pareto sensitivity information, a second-order Pareto surface representation, an iterative decision making strategy and a Pareto visualization tool assisting tradeoff analysis and decision making are the functionalities provided by this framework. In the iterative decision making strategy, the decision maker learns about the existing Pareto designs and iteratively modifies his/her preferences until satisfied.

Another interactive physical programming approach was developed by Huang et al. [9]. In this approach, an initial Pareto design is obtained using physical programming. Based on this solution, the designer specifies which objectives need to be improved and which objectives can be sacrificed. For each new preference structure, corresponding Pareto designs are obtained using physical programming. Then these Pareto designs are visualized and one that best satisfies the designer's preference is selected. If the designer is satisfied with the selected Pareto design, the optimization process is terminated. Otherwise, based on the Pareto design selected, a new iteration of interactive physical programming is implemented, until the designer is satisfied with one of the obtained Pareto designs. It must be noted that visualization of a Pareto design is achieved by drawing a bar chart in the preference space.

\subsection{Other methodological contributions}

Hernandez et al. [5] develop an LPP-based procedure for the formulation of compromise decision support problem in order to help a designer avoid the inefficient and ineffective process of setting preferences in the deviation function, while exploiting a designer's understanding of the problem. Messac [36] investigates the shortcomings of weight-based methods using analytical and numerical means.
He also shows the superiority of physical programming over weight-based methods through analytical, graphical and computational means. Messac et al. [45] provide a theoretical examination of the Pareto optimality of solutions obtained using PP. They conclude that all solutions obtained using PP are Pareto optimal. The issue of stability of optimal solutions with respect to user input parameters to express preferences is also investigated in this study. The conclusion is that PP yields an evenly distributed set of solutions for an evenly distributed set of preference input parameters. Messac and Mattson [44] develop a physical programming based Pareto frontier generation (PPPF) method. They showed that the effectiveness of the PPPF method is comparable to the Pareto frontier generation method based on the NBI method and superior to those based on the weighted sum and compromise programming methods. Sroka and Long [65] use a similar method to the one described in Messac and Mattson [44] for generating an even distribution of Pareto points. Messac and Chen [38] develop an optimization visualization approach by exploiting the formulation paradigm of PP. This approach allows for real-time decision making due to its ability of providing information on the status of the optimization process. Li et al. [20] develop a novel methodology based on the integration of LPP and non-dominated sorting genetic algorithm (NSGA-II) for multiobjective robust collaborative optimization. A collaborative multiobjective optimization methodology involving four main steps (viz., formulation, optimization, simulation and selection) is developed by Baril et al. [2]. LPP is integrated into the optimization step of this methodology. Baril et al. [2] propose a collaborative interactive multi-objective algorithm by integrating several concepts involving the payoff table, physical programming, non-linear goal programming, the stability sets and sets subtraction algorithm.

\section{Industrial Engineering Applications}

Industrial engineering applications of PP can be classified into five main categories: forward supply chains, reverse and closed-loop supply chains, production planning, reliability and maintenance and quality function deployment. 


\subsection{Forward supply chains}

Melachrinoudis et al. [33] use LPP to solve the relocation problem of a manufacturing/distribution facility. They consider a multitude of factors including cost, access to customers, access to suppliers, access to transportation infrastructure, tax incentives, labor quality and labor-management relations. Melachrinoudis et al. [32] develop an LPP model to reconfigure a warehouse network through consolidation and elimination. The factors considered in the study include relocation/consolidation costs, inbound and outbound transportation costs, warehousing costs, relocation costs, customer delivery time, and intangible factors, such as labor quality, labor-management relations and tax incentives. The LPP-based supplier selection model proposed by Mirakhorli et al. [48] considers four criteria (viz., purchasing price, transportation cost, quality, lead time and demand coverage).

\subsection{Reverse and closed-loop supply chains}

A reverse supply chain involves a series of activities for the retrieval of used products from consumers and remanufacturing or recycling them to recover their left-over market value. The combination of forward (traditional) and reverse supply chains is called a closed-loop supply chain Nukala and Gupta [53]. Researchers developed PP-based methodologies for two reverse and closed loop supply chain related issues: Network design and disassembly to order systems.

\subsubsection{Network Design (ND)}

Pochampally et al. [57] use LPP to identify potential facilities in a set of candidate recovery facilities operating in a region where a reverse supply chain is to be established. They model total cost involving transportation cost, cost of labor, inventory cost and fixed cost as a Class 1S criteria. The following criteria were modeled as Class 2S:

- Increment in quality of products at recovery facility.

- Ratio of throughput to supply of used products.

- Multiplication of throughput by disassembly time.

- Customer service rating of the recovery facility.
Pochampally et al. [58] propose a three-phase LPP approach for designing a reverse supply chain. Phase I involves the selection of economical products to re-process from a set of candidate cores. Total collection cost per period, total reprocessing cost per period, total disposal cost per period, periodical worth of loss-of-sale cost, periodical worth of investment cost are modeled as Class $1 \mathrm{~S}$ while Class 2S criteria involve total reuse revenue per period and total recycle revenue per period. In phase 2, potential recovery facilities are identified by using the criteria and classes defined in Pochampally et al. [57]. In phase 3, the right mix and quantities of products (used as well as re-processed) to be transported across the reverse supply chain is determined. Total retrieval cost per period is defined as Class $1 \mathrm{H}$ while total transportation cost per period, total re-processing cost per period and total inventory cost per period are formulated as Class $1 \mathrm{~S}$.

Nukala and Gupta [53] develop an LPP model for the strategic and tactical planning of a closed loop supply chain. The model when solved identifies simultaneously the most economical used-product to re-process in the closed-loop supply chain, the efficient production facilities and the right mix and quantity of goods to be transported across the supply chain. They model various cost criteria (viz., collection/retrieval cost, processing cost, transportation cost and disposal cost) as Class $1 S$ while revenue criteria (viz., reuse revenue, recycle revenue and new product sale revenue) are modeled as Class 2S. Pochampally et al. [61], [62] and Ilgin and Gupta [10] present similar models.

Pochampally et al. [60] integrate quality function deployment (QFD) and LPP to measure the "satisfaction level" of a reverse/closed-loop supply chain with respect to various performance measures (viz., reputation, innovation and improvement, public participation, facility potentiality, responsiveness, delivery reliability) and respective enablers. A similar model is presented in Pochampally et al. [62].

Pochampally and Gupta [59] apply LPP to the collection center selection problem. First, they define the following eight criteria: sigma level (SL), per capital income of people in residential area (PR), utilization of incentives from local government (UG), distance from residential 
area (DR), distance from highways (DH), incentives from local government (IG), space cost (SC), labor cost (LC). Then, for the sake of convenience, the similar criteria are combined into appropriate classes as follows: SC + LC (Class 1S), DR + DH (Class 1S). All remaining criteria (SL, PR, UG, IG) are considered individually and classified as Class 2S.

\subsubsection{Disassembly-to Order Systems (DTOS)}

The importance of product disassembly has increased in recent years due to its critical role in all product disposal options (e.g., recycling, remanufacturing). Disassembly process must be planned in an efficient way so as to increase the profitability of product recovery operations. Disassembly to order problem, an important disassembly process planning issue, involves the determination of the number of EOL products to process to fulfill a certain demand for products, parts and/or materials under a variety of objectives and constraints. Kongar and Gupta [13] develop an LPP model to solve a disassembly to order problem. The model provides the number of items to be disassembled for remanufacturing, recycling, storage and disposal. They consider nine criteria. Average customer satisfaction, average quality achievement, resale revenue, recycling revenue, total profit and number of recycled items are defined as Class 2S type. Average environmental damage and average environmental benefit are considered as Class 4S type. Number of disposed items is defined as Class 1S type. A similar model is presented in Lambert and Gupta [19]. Kongar and Gupta [14] model a DTO problem with five goals using LPP. Number of disposed items is classified as Class $1 \mathrm{~S}$, total profit and number of recycled items are defined as Class $2 \mathrm{~S}$ and environmental damage and customer satisfaction are modeled as Class 4S. Imtanavanich and Gupta [12] solve a multiperiod DTO problem using LPP based on four objectives, namely, profit (Class 2S), procurement cost (Class 1S), take-back cost (Class 1S), disposal cost (Class 1S). Imtanavanich and Gupta [11] integrate genetic algorithms and LPP to solve a DTO problem. LPP is used to calculate the fitness values in the GA process. Massoud and Gupta [30] develop an LPP-based solution approach to multi-period DTO problem by considering four objectives, namely maximization of profit (Class 2S), minimization of procurement cost (Class 1S), minimization of purchase cost (Class 1S), minimization of disposal cost (Class 1S). Ondemir and Gupta [54] use LPP to determine the optimum disassembly, refurbishment, disposal, recycling and storage plans in a demand-driven environment which utilizes the life-cycle data collected, stored and delivered by sensors and RFID tags.

\subsection{Production planning}

The first application of LPP in production planning was presented by Messac et al. [37]. Their LPP model minimizes cost and manufacturing time, while maximizing production rate. Maria et al. [28] apply LPP to production planning of a generic production system by considering machine yield rate and machine efficiency. Gulsun et al. [4] develop an LPP model for aggregate production planning. They determine the most appropriate plan by minimizing total production costs and the effects of hire/layoff decisions on the workforce motivation level. Both of these objectives were defined as Class $1 \mathrm{~S}$.

\subsection{Reliability and maintenance}

Redundancy allocation is the most frequently studied reliability problem in PP literature. Huang et al. [9] apply interactive physical programming to the reliability and redundancy apportionment of a five-stage over-speed protection system for a gas turbine. Tian and Zuo [70] use LPP to develop a multi-objective optimization model for redundancy allocation for multi-state series-parallel systems considering utility, cost and weight. In the LPP framework, the utility objective has Class-2S class function (maximization), while the cost and weight objectives have Class-1S class functions (minimization). Genetic algorithm (GA) is used to solve the proposed optimization model. The LPP-based multi-objective optimization model proposed by Tian et al. [71] jointly determines the optimal component state distribution and optimal redundancy for each stage based on two objectives, cost (Class 1S) and system utility (Class 2S). Kumar et al. [17] present a PP and conjoint analysis-based redundancy allocation model (PPCA-RAM) for a multistate series-parallel system. They define utility maximization as the $2 \mathrm{~S}$ class function and the cost, weight, and weight-volume minimization within the $1 \mathrm{~S}$ class. Tian et al. [69] use PP in condition-based maintenance optimization considering two optimization objectives, cost (Class 1S) and reliability (Class 
2S). Li et al. [23] propose a PP-based multiobjective optimization model for multi-state weighted series-parallel system optimal design. The model which is solved using a genetic algorithm maximizes system reliability and expected performance utility while minimizing investment system cost simultaneously.

\subsection{Quality Function Deployment}

Lai et al. [18] use LPP in quality function deployment (QFD) optimization by proposing a two-step approach. In the first step, the information required for LPP is collected through the use of traditional QFD approach and house of quality is constructed. Qualitative analysis of the design problem is also completed in this step. The second step involves mathematical modeling using LPP. The approach was applied to a software design problem.

\section{Mechanical Engineering Applications}

Mechanical engineering applications of PP can be classified into two main categories: design and control.

\subsection{Design}

Design of a complex system requires the simultaneous consideration of many constraints and conflicting objectives (design metrics). In $\mathrm{PP}$, the designer can specify ranges of different degrees of desirability for each design metric rather than specifying optimization weights. Due to this unique feature, PP has been used in many design optimization studies.

Chen et al. [3] apply PP to aircraft propulsion system design. Kovach et al. [16] integrate response surface methodology (RSM) and PP for the robust design of a tablet manufactured by a pharmaceutical company. The design characteristics considered include tensile strength, disintegration time and weight. Response functions for the mean and standard deviations of the design characteristics are estimated using RSM. Then, the attributes of each of the quality characteristics are classified and the designer's preferences are specified. A PP-based methodology is developed by Zhang [75] for 2D turbine airfoil design. Pressure loss, leading edge radius and trailing edge radius are defined as Class $1 \mathrm{~S}$ while the preference function for outflow angle is Class 3S. Tong et al. [72] optimize the design of gas-generator engines by considering two objectives, specific impulse of the engine (Class 2S) and thrust to weight ratio (Class 2S). Zhang [76] uses PP for aircraft conceptual parameter design. Li et al. [20] apply their multiobjective robust collaborative optimization technique to the design of a speed reducer.

PP was also used for multidisciplinary design optimization (MDO) which is a concurrent engineering design tool for large-scale system design that typically approaches the design problem by decomposing the system into its constituent subsystems. There is an intrinsic linkage between these subsystems through design, function and performance. McAllister et al. [31] integrate PP and collaborative optimization (a popular MDO framework) through the use of compromise decision support problem (DSP). In this integration, PP allows designers to formulate the problem using physically meaningful parameters to describe customer specified requirements while collaborative optimization is used to define the hierarchical design problem in a formulation that is reflective of the functional structure of system design problems. Optimization mechanics is provided by DSP. A race car design example is employed to illustrate the proposed framework. This example consists of two subsystem level analyses - force and aerodynamics - and incorporates two systemlevel objectives: (1) minimize lap time and (2) maximize normalized weight distribution. Minimization of rear wheel down force is also considered in the aerodynamics subsystem as a secondary objective. Li and Zhang [22] develop an MDO framework by integrating LPP and collaborative optimization.

Patel et al. [56] develop an approach to obtain sets of subsystem combinations that would perform successfully with the newly developed components. In this approach, PP is used to model the designer's preferences for both the local measures of merit (characteristic of a given subsystem) and the global measures of merit (characteristic of the entire system). A discrete programming algorithm, called the kth shortest path algorithm, is integrated with PP to find the best subsystem design combinations.

Suleman and Gonicalves [66] propose a multi objective optimization problem of an adaptive composite beam with piezoelectric actuators bonded to its surface. They optimize the size and placement of the actuator pairs by 
considering three concurrent objectives, namely, maximization of the actuation performance, minimization of the mass of the actuators and keeping the required actuation energy/voltage below specified values. The first objective is considered in two different ways. In the first, actuator performance is measured based on the maximization of the average vertical displacement at the free end of the cantilever beam. In this case, class of the preference function is $2 \mathrm{~S}$. In the second, they investigate the average vertical displacement at $\mathrm{y}=\mathrm{W} / 2$ and related it to the average vertical displacement at $\mathrm{y}=\mathrm{W}$ such that the former is maximized (Class 2S) and the latter is minimized (Class 1S). The class of the preference function associated with the second objective is $1 \mathrm{~S}$ while the third objective's preference function is defined as Class $1 \mathrm{H}$. Wilson et al. [74] design a vibration isolation mount using PP. All design preferences (viz., minimization of the peak transmissibility, minimization of the transmissibility at $3 \mathrm{~Hz}$, minimization of the transmissibility at $10 \mathrm{~Hz}$, minimization of the settling time and minimization of the peak actuator force) are modeled as Class 1S. Baril et al. [1] apply their collaborative multiobjective optimization methodology for designing product and apply the design for Six Sigma approach.

Luo et al. [26] present an application of PP to spacecraft rendezvous trajectory design with three objectives, namely, minimization of the time of flight (Class 1S), minimization of the total velocity characteristic (Class 1S) and maximization of the trajectory safetyperformance index (Class 2S). They combine PP and simulated annealing. After converting the multi-objective functions into a singleobjective function using PP, a feasible iteration optimization model is formulated using a Lambert algorithm. Then a simulated annealing algorithm is employed to locate the unperturbed two-body solution.

Martinez et al. [29] focus on the application of PP to the multi-criteria wing spar design optimization problem by considering four design metrics, namely, minimization of weight (Class 1S), minimization of cost (Class 1S), minimization of tip deflection (Class 1S), minimization of strength of components (Class $1 S$ ).

Huang et al. [6] develop an alternative interactive PP approach to the interactive PP approach proposed by Huang et al. [9]. In this approach, the preference ranges for each objective are fixed during the interactive $\mathrm{PP}$ procedure. After a Pareto solution is generated, a preference offset is added to the class function of each objective considering whether the designer would like to improve this objective or sacrifice the objective so as to improve other objectives. These preference offsets can be interpreted as the designer's tradeoff on the design objectives. The preference offsets are adjusted during the interactive physical programming procedure and an optimal solution that satisfies the designer's preferences is supposed to be obtained by the end of the procedure.

Huang et al. [7] present an application of fuzzy physical programming in optimal design of conic-cylindrical gear reduction unit. A pair of conic gears is used as high-speed gears, while a pair of cylindrical gears is used as the lowspeed gears. The objective is to minimize volume (Class 1S) and minimize difference of power delivered between high-speed gear and low-speed gear (Class 1S). Genetic Algorithms is applied to solve the formulated fuzzy physical programming model.

Messac and Hattis [40] apply PP to the preliminary design of the high speed civil transport (HSCT) plane. Design metrics include tank volume ratio (Class 1S), recurring cost per passenger seat (Class 1S), initial cost per passenger seat (Class 1S), propellant mass ratio (Class 2S), fuselage-length/wing-root-length ratio (Class 4S), engine inlet area (Class 4S), wing sweep-back angle (Class $4 \mathrm{~S}$ ) and number of passengers (Class $4 \mathrm{~S}$ ).

An application of the interactive fuzzy physical programming is presented by Zhang et al. [77] for the design of the spindle of internal grinder. They consider two design objectives, namely, minimization of the static bending deflection of the grinding wheel spindle extension (Class 1S) and the minimization of the weight of the entire spindle (Class 1S).

Another design issue considered by PP practitioners is the product families which are groups of related products derived from a product platform for the simultaneous consideration of economies of scale and satisfaction of a variety of customer requirements. Messac et al. [42] present a single-stage approach for simultaneously optimizing a product platform and the resulting family of products based on one or more 
scaling variables - variables that are used to instantiate the product platform by "stretching" or "shrinking"' it in one or more dimensions to satisfy a variety of customer requirements. The proposed approach is benchmarked considering the design of a family of ten universal electric motors from Simpson et al. [64]. The scaling parameter in this example was assumed to be motor stack length following the example in Simpson et al. [64]. However, determination of scaling and common variables is not a trivial task since it requires the consideration of the tradeoff between commonality and performance within a product family. Messac et al. [43] improve the methodology proposed by Messac et al. [42] by helping designers in the selection of common and scaling parameters in an efficient and effective way. They propose a product family penalty function to determine which parameters should be common throughout the product family and which should be the scaling variables. Applying this methodology to the design of a family of ten universal electric motors, they determine the radius as the scaling parameter. They showed that using radius as the scaling parameter provides significant improvement over using length.

Messac and Ismail-Yahaya [41] develop a PPbased method for robust design optimization (RDO) which seeks to maintain design feasibility under input variations. The following three objectives are considered in PP: 1. Minimization (Class 1) of the design metrics in order to maximize performance. 2. Maximization (Class 2) of the allowable variations of each design parameter in order to minimize manufacturing cost. 3. Minimization (Class 1) of the variations in design metrics in order to have robust performance in the face of the design parameter variations.

Mullur et al. [49] propose the use of LPP in decision matrix construction process. After applying this new approach to concept selection problem, they note the following advantages over the classical decision matrix construction: designers can obtain solutions on the non-convex regions of the Pareto frontier and there is no need for the specification of physically meaningless weights and ratings.

Huang and Tian [8] integrate neural networks and PP. The proposed methodology involves four steps: 1. A PP problem is solved to obtain the initial Pareto design $\mathrm{f} *$ and the corresponding design variables 2. The firstorder Pareto surface approximation around $\mathrm{f} *$ is obtained through the sensitivity analysis of the Pareto surface at $\mathrm{f} *$. The neural network model of the Pareto surface is built. 3. The candidate Pareto designs are generated, visualized and evaluated through the interactive decision making process. The neural network model of the designer's local preferences is built. 4 . The Pareto design that best satisfies the designer's local preferences is obtained using genetic algorithms. Finally, the final design is obtained by solving a corresponding compromise programming problem.

Li et al. [21] integrate physical programming and analytical target cascading (ATC). In this approach, the preference function of PP is used to determine the deviation between response and linking variables in ATC. Wang et al. [73] integrate linear physical programming and ATC by using the aggregate preference function in LPP as the objective function of ATC.

\subsection{Control}

Messac and Wilson [47] apply PP to synthesize a controller that solves the two-mass benchmark problem. They show that the use of PP leads to a controller that meets all the aspects of the benchmark problem: nominal and worst-case settling time, nominal and worst-case controller effort, and noise amplification. Messac [35] investigates the use of PP in control-structure integrated design.

\section{Other Applications}

Nagrath et al. [50] and Nagrath et al. [52] present an LPP approach for analyzing the multi-objective flux analysis of metabolic networks. The developed framework was first applied to compute a set of multi-objective optimal solutions for various pairs of objectives relevant to hepatocyte function (urea secretion, albumin, NADPH and glutathione syntheses) in bio-artificial liver systems. Next, simultaneous analysis of the optimal solutions for three objectives was carried out. All four objective functions are maximized. Hence, they are defined as “'Class-2S"'.

Tian et al. [68] propose a fuzzy PP approach for the optimization of through passenger train plan. Genetic algorithms is used in solving the fuzzy physical programming model 
Kongsuwan and Sangmun [15] develop a fourstep LPP-based methodology to achieve a trade-off between the quality and limited resources in the development of information security systems. The first step involves the selection of quality factors relating to the product development cycle. In the second step, for each quality factor, relative amount of resources required to achieve 100 percent of quality levels, objectives, and design preferences are determined. LPP is used in the third step to find the optimum quality levels for all quality factors based on the information from Step 2. In the last step, the optimum costs for all quality factors are calculated by utilizing the quality-to-cost transformation.

Ma and Dong [27] apply LPP to web service selection problem which involves the selection of proper candidate web service from each web service classes to satisfy the request of a user. They consider four criteria related with service, namely, price, duration(s), reliability and availability. Class functions of price and duration are 1-S while reliability and availability belong to 2-S class functions.

Nagrath et al. [51] develop a PP-based multiobjective framework for linear gradient chromatography. In the first step of this methodology, a set of Pareto solutions are generated for model protein separations for both bi-objective (production rate and yield) and tri-objective (production rate, yield, and product pool concentration) scenarios. The second step involves the application of PP for the quantitative evaluation of the optimal solutions for tertiary protein mixtures. Design metrics considered include production rate (Class 2S), production rate times yield (Class 2S), product pool concentration (Class 2S), solubility constraint (Class $1 \mathrm{H}$ ), yield (Class $2 \mathrm{~S}$ and Class $2 \mathrm{H}$ ) and purity (Class $2 \mathrm{H}$ ).

Messac et al. [46] integrate Genesis and PP for the optimization of large-scale rigidified inflatable structures for housing. An iteration of the proposed methodology involves the following steps:

- Step 1: Genesis performs structural analysis and optimization and generates responses (e.g., stress, buckling load factor, volume, etc.).

- Step 2: The response values are passed as design objectives to PP, where the aggregate objective function (AOF) value is computed.

- Step 3: The resulting AOF value is passed back to Genesis, where it is minimized.

The iterations are repeated until an optimal solution is found.

Lin et al. [25] integrate a topology optimization method-solid isotropic material with penalization (SIMP) with PP for the multiobjective optimization of compliant mechanisms in the field of continuum-type topology optimization. The feasibility of the proposed methodology is demonstrated by presenting two widely studied examples, namely the compliant force inverter and the compliant gripper.

Onut et al. [55] employ LPP to allocate energy resources among subgroups of Turkish manufacturing industry. They consider the following objectives: minimization of cost, maximization of system efficiency, maximization of employment, minimization of carbon, sulphur and nitrogen emissions, maximization of the reliability of energy resources, maximization of total convenience degree and maximization of the utilization of locally produced energy resources.

$\mathrm{Li}$ et al. [24] solve the software release time problem using physical programming based on three objectives (viz. cost, reliability and risk).

\section{Conclusions}

In this study, we presented a review of the state of the art literature on physical programming. After presenting an introduction to physical programming, the papers from the PP literature were reviewed by considering four categories (viz., methodological papers (MP), industrial engineering applications (IEA), mechanical engineering applications (MEA) and other applications (OA)). Table 1 shows the cited references organized into appropriate categories. Figure 4 presents the number of publications in each category. 


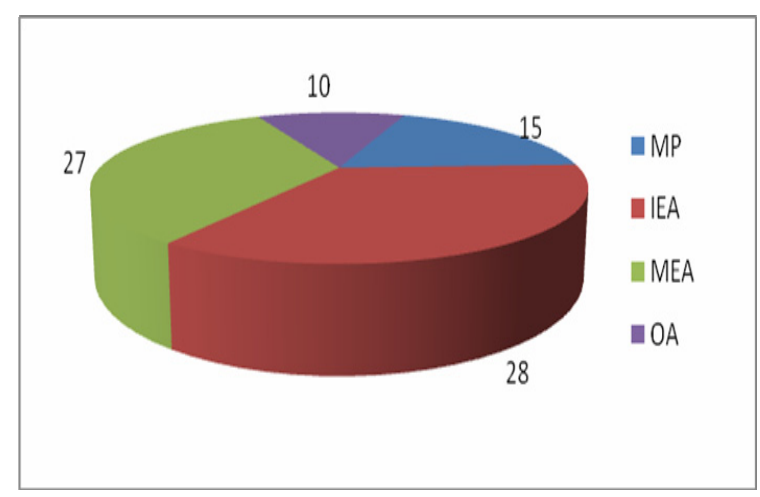

Figure 4. Number of publications in each category

Based on this review, we can present the following general points on the current and future research directions in physical programming:

- Majority of the studies is on the application of PP to a specific multi criteria decision making problem.

- Design of products or structures is by far the most frequently studied MCDM problem considering the mechanical engineering related applications of PP. Figure 5 presents the number of papers in design (D) and control (C).

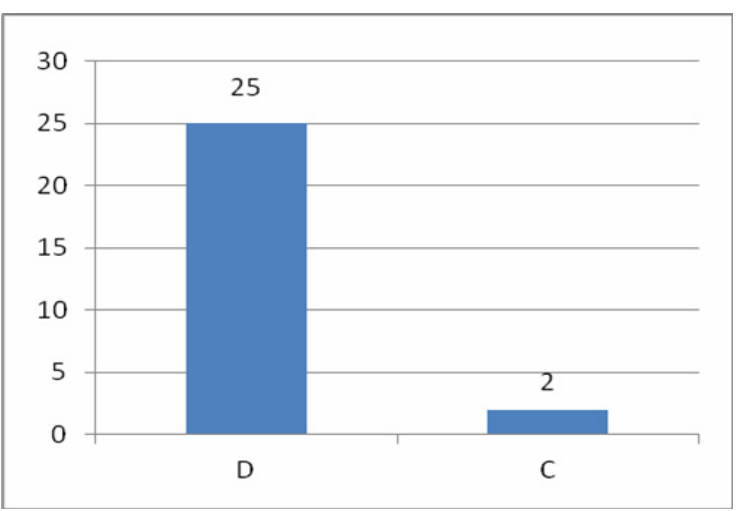

Figure 5. Number of publications in each area of mechanical engineering

- In theoretical papers, the common objective is the simplification of PP algorithm and optimization process by modifying the preference functions.

- Among the variants of original PP algorithm, Linear Physical programming is the most popular one. Figure 6 presents the number of publications in each variant of PP.

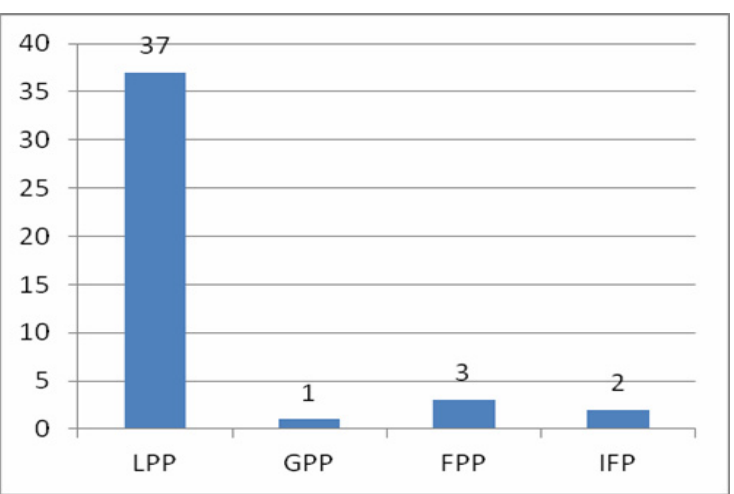

Figure 6. Number of publications in each variant of PP

- The applications of PP in industrial engineering are limited to forward supply chain (FSC) and reverse and closed-loop supply chain (RCLSC) design, production planning (PP), reliability and maintenance (R\&M) and quality function deployment (QFD). In some of these areas, there are only a few publications. Hence, PP should also be applied to other areas in IE (viz., quality management, facilities and layout planning, project management etc.). In addition, more studies should be carried out in the existing application areas in order to fully understand the potential and applicability of PP in these areas. The number of publications in each area of industrial engineering is presented in Figure 7.

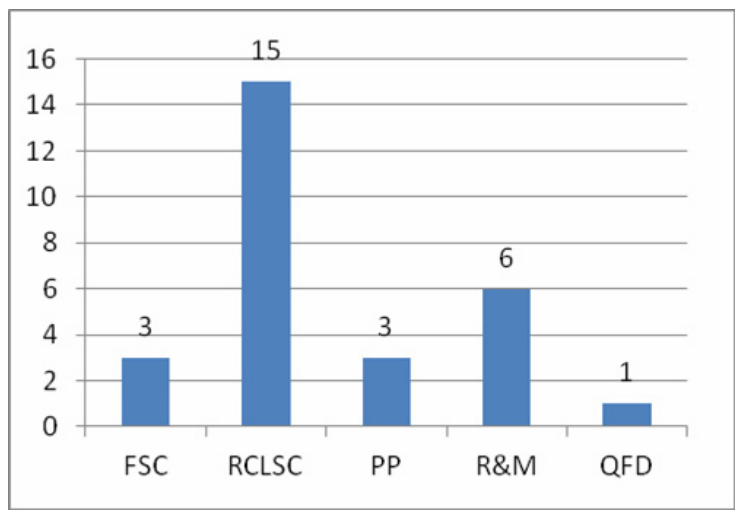

Figure 7: Number of publications in each area of industrial engineering

- The formulation and solution of PP models requires mathematical programming knowledge. In addition, programming languages or optimization software must be employed to determine the optimal solution. The development of user-friendly programs which can construct the mathematical programming model based on the preferences defined by the user and carry out the optimization process 
automatically may minimize the need for mathematical programming and computer programming expertise.

Table 1. Classification of references based on problem domain

\begin{tabular}{|l|l|l|l|}
\hline \multicolumn{2}{|l|}{ Category } & & $\begin{array}{l}34,39,36,67,38,5,45, \\
44,68,9,63,2,20,1,65\end{array}$ \\
\hline MP & & & $33,32,48$ \\
\hline IEA & FSC & & $37,58,53,60,62,59,10$ \\
\hline & R\&CLSC & ND & $13,19,12,11,14,30,54$ \\
\hline & & DTOS & $17,28,4$ \\
\hline & PP & & $37,49,23$ \\
\hline \multirow{3}{*}{ MEA } & R\&M & & $9,70,71,17,69,23$ \\
\cline { 2 - 4 } & QFD & & 18 \\
& & & $66,74,3,40,29,42,43$, \\
& & & $41,56,49,7,6,8,31,72$, \\
& & & $77,16,26,75,2,25,76$, \\
\hline & C & & $47,35,22$ \\
\hline OA & & & $68,46,51,27,15,50,25$, \\
& & & $55,52,24$ \\
\hline
\end{tabular}

\section{REFERENCES}

1. BARIL, C., S. YACOUT, B. CLEMENT, An Interactive Multi-objective Algorithm for Decentralized Decision Making in Product Design. Optimization and Engineering, vol. 13, no. 1, 2012, pp. 121-150.

2. BARIL, C., S. YACOUT, B. CLÉMENT, Design for Six Sigma through Collaborative Multi-objective Optimization. Computers \& Industrial Engineering, vol. 60, no. 1, 2011, pp. 43-55.

3. CHEN, W., A. SAHAI, A. MESSAC, G. SUNDARARAJ, Exploration of the Effectiveness of Physical Programming in Robust Design. Journal of Mechanical Design, vol. 122, no. 2, 2000, pp. 155-163.

4. GULSUN, B., G. TUZKAYA, U. R. TUZKAYA, S. ONUT, An Aggregate Production Planning Strategy Selection Methodology based on Linear Physical Programming. International Journal of Industrial Engineering, vol. 16, no. 2, 2009, pp. 135-146.

5. HERNANDEZ, G., J. K. ALLEN, F. MISTREE, The Compromise Decision Support Problem: Modeling the Deviation Function as in Physical Programming. Engineering Optimization, vol. 33, no. 4, 2001, pp. 445-471.

6. HUANG, H.-Z., Z.-G. TIAN, M. ZUO, Multiobjective Optimization of Threestage Spur Gear Reduction Units using
Interactive Physical Programming. Journal of Mechanical Science and Technology, vol. 19, no. 5, 2005a, pp. 1080-1086.

7. HUANG, H.-Z., X. ZHANG, Z.-G. TIAN, C.-S. LIU, Y.-K. GU, Optimal Design of Conic-Cylindrical Gear Reduction Unit Using Fuzzy Physical Programming. Intelligent Information Processing II, Springer, Boston, 2005b, pp. 191-200.

8. HUANG, H., Z. TIAN, Application of Neural Network to Interactive Physical Programming. Advances in Neural Networks - ISNN 2005, Springer Berlin / Heidelberg.2005, pp. 194-205.

9. HUANG, H., Z. TIAN, Y. GU, Reliability and Redundancy Apportionment Optimization using Interactive Physical Programming. International Journal of Reliability, Quality and Safety Engineering, vol. 11, no. 3, 2004, pp. 213-222.

10. ILGIN, M. A., S. M. GUPTA, Remanufacturing Modeling and Analysis. Boca Raton, Florida, CRC Press, 2012.

11. IMTANAVANICH, P., S. M. GUPTA, Evolutionary Computation with Linear Physical Programming for Solving a Disassembly-to-Order System. Proceedings of the SPIE International Conference on Environmentally Conscious Manufacturing VI, Boston, Massachusetts, 2006a, pp. 30-41.

12. IMTANAVANICH, P., S. M. GUPTA, Linear Physical Programming Approach for a Disassembly-to-Order System under Stochastic Yields and Product's Deterioration. Proceedings of the 2006 POMS Meeting, Boston, MA 2006b, Paper no. 004-0213.

13. KONGAR, E., S. M. GUPTA, Disassembly-to-Order System using Linear Physical Programming. Proceedings of 2002 IEEE International Symposium on Electronics and the Environment, San Francisco, California, 2002, pp. 312-317.

14. KONGAR, E., S. M. GUPTA, Solving the Disassembly-to-Order Problem using Linear Physical Programming. International Journal of Mathematics in Operational Research, vol. 1, no. 4, 2009, pp. 504-531. 
15. KONGSUWAN, P., S. SANGMUN, Integrating Physical Programming to Information Security System Management. Proceedings of the 11th International Conference on Advanced Communication Technology, Phoenix Park, South Korea, 2009, pp. 143-148.

16. KOVACH, J., B. CHO, J. ANTONY, Development of an Experiment-based Robust Design Paradigm for Multiple Quality Characteristics using Physical Programming. The International Journal of Advanced Manufacturing Technology, vol. 35, no. 11, 2008, pp. 1100-1112.

17. KUMAR, V., M. TRIPATHI, M. PANDEY, M. TIWARI, Physical Programming and Conjoint Analysisbased Redundancy Allocation in Multistate Systems: a Taguchi Embedded Algorithm Selection and Control (TAS\&C) Approach. Proceedings of the Institution of Mechanical Engineers, Part O: Journal of Risk and Reliability, vol. 223, no. 3, 2009, pp. 215-232.

18. LAI, X., M. XIE, K.-C. TAN, QFD Optimization using Linear Physical Programming. Engineering Optimization, vol. 38, no. 5, 2006, pp. 593-607.

19. LAMBERT, A. J. D., S. M. GUPTA, Disassembly Modeling for Assembly, Maintenance, Reuse, and Recycling. Boca Raton, Florida, CRC Press, 2005.

20. LI, H., M. MA, Y. JING, A New Method based on LPP and NSGA-II for Multiobjective Robust Collaborative Optimization. Journal of Mechanical Science and Technology, vol. 25, no. 5, 2011a, pp. 1071-1079.

21. LI, L., X. CHU, L. GAO, Q. BO, X. SHAO, Analytical Target Cascading based on Physical Programming. Proceedings of IEEE International Conference on Systems Man and Cybernetics, Istanbul, Turkey 2010, pp. 3060-3067.

22. LI, L., Y.-H. ZHANG, Study on Multiobjective Optimization Based on the Integration of Linear Physical Programming within Collaborative Optimization. Proceedings of the International Conference on Fuzzy Systems and Knowledge Discovery, Sichuan, China, 2012, pp. 2711-2714.

23. LI, W., M. J. ZUO, R. MOGHADDASS, Optimal Design of a Multi-State Weighted Series-Parallel System Using Physical Programming and Genetic Algorithms. Asia-Pacific Journal of Operational Research, vol. 28, no. 4, 2011b, pp. 543-562.

24. LI, X., M. XIE, N. SZU HUI, MultiObjective Optimization Approaches to Software Release Time Determination. Asia-Pacific Journal of Operational Research, vol. 29, no. 3, 2012, pp.1-19.

25. LIN, J., Z. LUO, L. TONG, A New Multiobjective Programming Scheme for Topology Optimization of Compliant Mechanisms. Structural and Multidisciplinary Optimization, vol. 40, no. 1, 2010, pp. 241-255.

26. LUO, Y., G. TANG, G. PARKS, Multiobjective Optimization of Perturbed Impulsive Rendezvous Trajectories using Physical Programming. Journal of Guidance, Control, and Dynamics, vol. 31, no. 6, 2008, pp. 1829-1832.

27. MA, X., B. DONG, Linear Physical Programming-Based Approach for Web Service Selection. Proceedings of the International Conference on Information Management, Innovation Management and Industrial Engineering, Taipei, Taiwan, 2008, pp. 398-401.

28. MARIA, A., C. MATTSON, A. ISMAILYAHAYA, A. MESSAC, Linear Physical Programming for Production Planning Optimization. Engineering Optimization, vol. 35, no. 1, 2003, pp. 19-37.

29. MARTINEZ, M., A. MESSAC, M. RAISROHANI, Manufacturability-based Optimization of Aircraft Structures using Physical Programming. AIAA Journal, vol. 39, no. 3, 2001, pp. 517-525.

30. MASSOUD, A., S. M. GUPTA, Linear Physical Programming for Solving the Multi-criteria Disassembly-to-Order Problem under Stochastic Yields, Limited Supply, and Quantity Discount. Proceedings of 2010 Northeast Decision Sciences Institute Conference, Alexandria, Virginia, 2010, pp. 474-479. 
31. MCALLISTER, C. D., T. W. SIMPSON, K. HACKER, K. LEWIS, A. MESSAC, Integrating Linear Physical Programming within Collaborative Optimization for Multiobjective Multidisciplinary Design Optimization. Structural and Multidisciplinary Optimization, vol. 29, no. 3, 2005, pp. 178-189.

32. MELACHRINOUDIS, E., A. MESSAC, $\mathrm{H}$. MIN, Consolidating a Warehouse Network: A Physical Programming Approach. International Journal of Production Economics, vol. 97, no. 1, 2005, pp. 1-17.

33. MELACHRINOUDIS, E., H. MIN, A. MESSAC, The Relocation of a Manufacturing/Distribution Facility from Supply Chain Perspectives: A Physical Programming Approach. Advances in Management Science, Multicriteria Applications. Kenneth Laurence, editor, Elsevier Science Inc., Vol. 10, 2000, pp.15-39.

34. MESSAC, A., Physical Programming: Effective Optimization for Computational Design. AIAA Journal, vol. 34, no. 1, 1996, pp. 149-158.

35. MESSAC, A., Control-structure Integrated Design with Closed-form Design Metrics using Physical Programming. AIAA Journal, vol. 36, no. 5, 1998, pp. 855-864.

36. MESSAC, A., From Dubious Construction of Objective Functions to the Application of Physical Programming. AIAA Journal, vol. 38, no. 1, 2000, pp. 155-163.

37. MESSAC, A., W. M. BATAYNEH, A. ISMAIL-YAHAYA, Production Planning Optimization with Physical Programming. Engineering Optimization, vol. 34, no. 4, 2002a, pp. 323 - 340.

38. MESSAC, A., X. CHEN, Visualizing the Optimization Process in Real-time using Physical Programming. Engineering Optimization, vol. 32, no. 6, 2000, pp. 721-747.

39. MESSAC, A., S. M. GUPTA, B. AKBULUT, Linear Physical Programming: A New Approach to Multiple Objective Optimization.
Transactions on Operational Research, vol. 8, no. 2, 1996, pp. 39-59.

40. MESSAC, A., P. HATTIS, Physical Programming Design Optimization for High Speed Civil Transport. Journal of Aircraft, vol. 33, no. 2, 1996, pp. 446-449.

41. MESSAC, A., A. ISMAIL-YAHAYA, Multiobjective Robust Design using Physical Programming. Structural and Multidisciplinary Optimization, vol. 23, no. 5, 2002, pp. 357-371.

42. MESSAC, A., M. P. MARTINEZ, T. W. SIMPSON, Effective Product Family Design Using Physical Programming. Engineering Optimization, vol. 34, no. 3, 2002b, pp. 245 - 261.

43. MESSAC, A., M. P. MARTINEZ, T. W. SIMPSON, Introduction of a Product Family Penalty Function Using Physical Programming. Journal of Mechanical Design, vol. 124, no. 2, 2002c, pp. 164-172.

44. MESSAC, A., C. MATTSON, Generating Well-distributed Sets of Pareto Points for Engineering Design using Physical Programming. Optimization and Engineering, vol. 3, no. 4, 2002, pp. 431-450.

45. MESSAC, A., C. SUKAM, E. MELACHRINOUDIS, Mathematical and Pragmatic Perspectives of Physical Programming. AIAA Journal, vol. 39, no. 5, 2001, pp. 885-893.

46. MESSAC, A., S. VAN DESSEL, A. A. MULLUR, A. MARIA, Optimization of Large-scale Rigidified Inflatable Structures for Housing using Physical Programming. Structural and Multidisciplinary Optimization, vol. 26, no. 1, 2004, pp. 139-151.

47. MESSAC, A., B. WILSON, Physical Programming for Computational Control. AIAA Journal, vol. 36, no. 2, 1998, pp. 219-226.

48. MIRAKHORLI, A., M. H. FARAHANI, F. RAMTIN, New Approach in Supplier Selection using Linear Physical Programming. Proceedings of IEEE/INFORMS International Conference on Service Operations, Logistics and Informatics, Chicago, IL, 2009, pp. 47-51. 
49. MUlluR, A., C. A. MATTSON, A. MESSAC, New Decision Matrix based Approach for Concept Selection using Linear Physical Programming. Proceedings of the AIAA/ASME/ASCE/AHS Structures, Structural Dynamics, and Materials Conference, Norfolk, VA, 2003, Paper No: AIAA 2003-1446.

50. NAGRATH, D., M. AVILA-ELCHIVER, F. BERTHIAUME, A. W. TILLES, A. MESSAC, M. L. YARMUSH, Soft Constraints-based Multiobjective Framework for Flux Balance Analysis. Metabolic Engineering, vol. 12, no. 5, 2010, pp. 429-445.

51. NAGRATH, D., B. W. BEQUETTE, S. M. CRAMER, A. MESSAC, Multiobjective Optimization Strategies for Linear gradient Chromatography. AIChE Journal, vol. 51, no. 2, 2005, pp. 511-525.

52. NAGRATH, D., C. CANEBA, T. KAREDATH, N. BELLANCE, Metabolomics for Mitochondrial and Cancer Studies. Biochimica et Biophysica Acta (BBA) - Bioenergetics, vol. 1807, no. 6, 2011, pp. 650-663.

53. NUKALA, S., S. M. GUPTA, Strategic and Tactical Planning of a Closed-Loop Supply Chain Network: A Linear Physical Programming Approach. Proceedings of the 2006 POMS Meeting, Boston, MA 2006, Paper No: 004-0210.

54. ONDEMIR, O., S. M. GUPTA, Orderdriven Component and Product Recovery for Sensor-embedded Products (SEPS) Using Linear Physical Programming. Proceedings of the 41st International Conference on Computers \& Industrial Engineering, Los Angeles, CA 2011, pp. 714-719.

55. ONUT, S., U. R. TUZKAYA, G. TUZKAYA, B. GULSUN, A MultiObjective Energy Resource Allocation Model for Turkish Manufacturing Industry using Linear Physical Programming. International Journal of Innovative Computing, Information and Control, vol. 7, no. 6, 2011, pp. 3147-3169.

56. PATEL, M., K. LEWIS, A. MARIA, A. MESSAC, System Design through Subsystem Selection using Physical
Programming. AIAA Journal, vol. 41, no. 6, 2003, pp. 1089-1096.

57. POCHAMPALLY, K. K., S. GUPTA, S. KAMARTHI, Identification of Potential Recovery Facilities for Designing a Reverse Supply Chain Network using Physical Programming. Proceedings of the SPIE International Conference on Environmentally Conscious Manufacturing III, Providence, Rhode Island, 2003, pp. 139-146.

58. POCHAMPALLY, K. K., S. M. GUPTA, A Linear Physical Programming Approach for Designing a Reverse Supply Chain. Proceedings of the Fifth International Conference on Operations and Quantitative Management Seoul, South Korea, 2004, pp. 261-269.

59. POCHAMPALLY, K. K., S. M. GUPTA, Use of Linear Physical Programming and Bayesian Updating for Design Issues in Reverse Logistics. International Journal of Production Research, vol. 50, no. 5, 2012, pp. 1349-1359.

60. POCHAMPALLY, K. K., S. M. GUPTA, K. GOVINDAN, Metrics for Performance Measurement of a Reverse/Closed-loop Supply Chain. International Journal of Business Performance and Supply Chain Modelling, vol. 1, no. 1, 2009a, pp. 8-32.

61. POCHAMPALLY, K. K., S. NUKALA, S. M. GUPTA, Quantitative DecisionMaking Techniques for Reverse/ClosedLoop Supply Chain Design. Environment Conscious Manufacturing, S. M. Gupta and A. J. D. Lambert (Editors), Boca Raton, Florida, USA, CRC Press, 2008, pp. 105-214.

62. POCHAMPALLY, K. K., S. NUKALA, S. M. GUPTA, Strategic Planning Models for Reverse and Closed-Loop Supply Chains. Boca Raton, Florida, USA, CRC Press, 2009b.

63. SANCHIS, J., M. A. MARTÍNEZ, X. BLASCO, G. REYNOSO-MEZA, Modelling Preferences in Multi-objective Engineering Design. Engineering Applications of Artificial Intelligence, vol. 23, no. 8, 2010, pp. 1255-1264.

64. SIMPSON, T. W., J. R. A. MAIER, F. MISTREE, Product Platform Design: 
Method and Application. Research in engineering Design, vol. 13, no. 1, 2001, pp. 2-22.

65. SROKA, M., D. LONG, Exploring Metric Sensitivity of Planners for Generation of Pareto Frontiers. Proceedings of the Sixth Starting AI Researchers' Symposium, Montpellier, France, 2012, pp. 306-317.

66. SULEMAN, A., M. GONICALVES, Multi-objective Optimization of an Adaptive Composite Beam using the Physical Programming Approach. Journal of Intelligent Material Systems and Structures, vol. 10, no. 1, 1999, pp. 56-70.

67. TAPPETA, R., J. RENAUD, A. MESSAC, G. SUNDARARAJ, Interactive Physical Programming: Tradeoff Analysis and Decision Making in Multicriteria Optimization. AIAA Journal, vol. 38, no. 5, 2000, pp. 917-926.

68. TIAN, Z.-G., H.-Z. HUANG, L.-W. GUAN, Fuzzy Physical Programming and Its Application in Optimization of Through Passenger Train Plan, Proceedings of the International Conference on Traffic and Transportation Studies, Guilin, China, 2002, pp. 498-503.

69. TIAN, Z., D. LIN, B. WU, Condition based Maintenance Optimization Considering Multiple Objectives. Journal of Intelligent Manufacturing, vol. 23, no. 2, 2012, pp. 333-340.

70. TIAN, Z., M. ZUO, Redundancy Allocation for Multi-state Systems using Physical Programming and Genetic Algorithms. Reliability Engineering \& System Safety, vol. 91, no. 9, 2006, pp. 1049-1056.

71. TIAN, Z., M. J. ZUO, H. HUANG, Reliability-redundancy Allocation for Multi-state Series-Parallel Systems. IEEE Transactions on Reliability vol. 57, no. 2, 2008, pp. 303-310.
72. TONG, X.-Y., G.-B. CAI, Y.-T. ZHENG, J. FANG, Optimization of System Parameters for Gas-generator Engines. Acta Astronautica, vol. 59, no. 1-5, 2006, pp. 246-252.

73. WANG, T.-T., X.-K. CHEN, Y. LIN, Multi-objective Optimization Based on the Integration of Linear Physical Programming within Analytical Target Cascading. Proceedings of the 4th International Conference on Biomedical Engineering and Informatics, Shanghai, China 2011, pp. 2286-2289.

74. WILSON, B. H., C. ERIN, A. MESSAC, Optimal Design of a Vibration Isolation Mount using Physical Programming. Journal of Dynamic Systems, Measurement and Control, vol. 121, no. 2, 1999, pp. 171-178.

75. ZHANG, N., 2D Turbine Airfoil Optimization using Physical Programming. Proceedings of the International Conference on Mechatronics and Automation, Xi'an, China 2010, pp. 852-856.

76. ZHANG, N., Physical Programming based Multidisciplinary Optimization for Aircraft Conceptual Parameter Design. Proceedings of the Chinese Control and Decision Conference, Mianyang, China 2011, pp. 2387-2392.

77. ZHANG, X., H.-Z. HUANG, L. YU, Fuzzy preference based Interactive Fuzzy Physical Programming and its application in multi-objective optimization. Journal of Mechanical Science and Technology, vol. 20, no. 6, 2006, pp. 731-737. 